\title{
Offering Urban Spaces for Community Gardens: Implementation, Development, and Resilience in Stockholm, Sweden ${ }^{1}$
}

\author{
Madeleine Bonow, Maria Normark, Sabine Lossien
}

\begin{abstract}
One way of using public green spaces is to allow cultivation by citizens. Community gardening has proven to have many social benefits and can undoubtedly contribute to a sustainable society in a variety of ways. Yet while being clearly attractive for both citizens and officials, it does not always flourish in practice. In this study we draw on interviews with park engineers working in the city of Stockholm to analyze why community gardening is not more prevalent, despite the clearly existing political and popular will to promote it. The study shows that there are significant differences between Stockholm City's district administrations. Through applying implementation theory, we show that relatively small variations in local resources, expertise, and interests fundamentally shape the outcome of community gardening initiatives. It is also shown that unclear guidelines and a lack of horizontal and vertical communication constitute institutional barriers to the implementation, development, and resilience of community gardening in the districts of Stockholm.
\end{abstract}

KEYWORDS community gardening, implementation theory, institutional barriers, Stockholm, Sweden

\section{Introduction}

Community gardening has increased in the world's cities in recent years, due, no doubt, to its many inherent attractions and advantages (see, for example, van der Jagt et al. 2017). Relevant initiatives have come from various actors at varying levels (Nemoto and Biazoti 2017; Pölling 2016; van der Jagt et al. 2017). And as it is in many cities, so it is in Stockholm, with interest in community gardening having increased in recent years (Stockholms Stad 2013). Community gardening, given its positive effects, is considered a viable resource in Stockholm and is seen as part of the city's urban planning and sustainable development. However, as we noted in our earlier study of community gardeners, the prevalence of success differs markedly between Stockholm's various district areas (Bonow and Normark 2018).

Sociální studia / Social Studies 1/2020. Pp. 71-86. ISSN 1214-813X.

1 The research reported in this paper was funded by the Foundation for Baltic and East European Studies, dnr 72/14. The authors would like to thank all the interviewees from whom the data were collected for the use in this paper, and also the editors of this special issue and the anonymous referees who had valuable inputs on the text. 
The earlier study presented gardeners' perspectives and local experiences in their areas, which led us to the conclusion that the areas are different. In this study we focus on the perspectives of the park engineers, drawing on their experiences and knowledge in order to investigate the larger organizational patterns and why the development of community gardens is relatively slow and uneven. The park engineers are eminently suitable to take part in this study because they work with community gardening in practice at the local level. They also put the city's guidelines on community gardening into practice in the districts and oversee their management. The study presented is largely based on interviews with park engineers from nine of the 14 districts in Stockholm.

The overall aim of this paper is therefore to investigate the structural conditions and frames for community gardening in the city of Stockholm. We define community gardening as cooperative cultivation by groups of individuals or associations working on municipal land. Through an implementation theory analysis, we describe how varying administrative conditions result in unnecessary obstacles for community gardening development. In doing so we contribute to the growing body of literature that exists about city governance in relation to community gardening and thus generate knowledge about what is needed to increase the phenomenon's occurrence and success in specific city contexts.

\section{Previous Research}

Earlier research emphasizes the crucial role played by various actors' support and their cooperation in the development of urban gardening (Prové et al. 2016; van der Jagt et al. 2017) and that both so-called bottom-up and top-down initiatives are important (McClintock 2014; Prové et al. 2016; van der Jagt 2017). Tornaghi (2014) regards urban gardening as a grassroots singularity that is anchored in urban counterculture, acting as a participatory tool to bridge the divide between policymakers and grass-roots groups. Urban gardening can thus be understood as an expression of citizens' disposition to give their voice to urban space planning (Bonow and Normark 2018; Certomà and Notteboom 2017). Urban gardening is, then, an important activity through which residents can influence politics and their local environment. Indeed, the extent of their influence is crucial to the success of urban gardening (Nemoto and Biazoti 2017; van der Jagt 2017). Research also shows that support from the municipality and other government institutions is highly important, too (Prové et al. 2016; Redwood 2009), despite - perhaps because of - the fact that most initiatives usually come from below. This is because the governing officials, for example, provide the land, set the guidelines, and in many cases contribute with other resources (van der Jagt et al. 2017).

A recent Swedish $\mathrm{PhD}$ dissertation shows that community gardening is often positioned as a solution to a variety of problems that affect urban space, and that the discourse of community gardening includes many elements such as concerns about climate change, community cohesion, participation, integration, and urban infrastructure. In addition, community gardening is emphasized as part of the strategy for fulfilling global sustainability goals in all of the major cities in Sweden - Stockholm, Gothenburg, and Malmö (Åberg 2019: 51). Although commitment from administrators has grown across the board, there are varying approaches to realizing the objective of increasing the number of community gardens 
in Sweden. In Gothenburg the property management administration is currently working with various organizations which aim towards larger-scale agriculture (plants and livestock) in or near the city (Göteborg stad 2019). In Malmö there is an urban garden network managed by the local municipality (stadsodlingmalmo.se 2019). In Stockholm, in contrast, there is no network or organization with links to the formal governance for community gardeners, and Bonow and Normark's study has shown that the development of community gardening in Stockholm is seriously hampered by vague responsibilities for leadership and unclear expectations of the outcome (Bonow and Normark 2018).

Furthermore, the result of the study by Kaczorowska et al. (2015) shows that the role of institutions in integrating ecosystem services is critical, likewise the networks of actors involved (Kaczorowska et al. 2015: 210). They also believe that there cannot be a general solution for the integration of ecosystem services in the planning process; instead, the specifics of local conditions must always be considered. The results of the studies on ecosystem services and green habitats in Stockholm are interesting to consider in relation to community gardening, as these areas are very close to each other. It has also been argued that the spread, design, and functionality of community gardening in a city depends on the city's context (Cockrall-King 2012: 312; Prové et al. 2016; van der Jagt 2017), just as in the case of ecosystem services in Stockholm. How difficulties are solved and how the support for community gardening is structured depends on the social, historical, political, and material contexts (Prové et al. 2016; van der Jagt 2017). There is, therefore, no single, global strategy for the successful implementation of community gardening initiatives (Prové et al. 2016). However, based on the previous research outlined here we can see that certain common factors are crucial for the success of community gardening (success being defined as the endurance and sustainability over time of a number of gardens). The key factors are: strong support from various actors; the presence of both bottom-up and top-down initiatives; government goals and guidelines that are clear and expressed in the form of guiding documentation; the availability of resources (land, money, technical support, information, and expertise); and the need for food production.

\section{Implementation Theory}

In 1973, Pressman and Wildavsky (1973) stated that implementation failure was more likely to occur when plans are based on incorrect causal assumptions between policies and desired outcomes. Furthermore, there was a disparity between outcomes and plan objectives largely due to the fact that policymakers did not recognize the difficulty of coordinating activities, competing interests, and the diverse agencies involved in implementation (Pressman and Wildavsky 1973). While Pressman and Wildavsky discussed failure mechanisms of implementation in their study, Sabatier and Mazmanian (1983) discussed success mechanisms. According to Sabatier and Mazmanian, the six key criteria determining implementation success are: clear and consistent objectives; accurate causal linkages between objectives and actions; a sympathetic agency with adequate resources and authority to implement the plan; the presence of skilled and committed implementation managers; public and stakeholder support; and a supportive socioeconomic and policy environment. 
Today there has been a development of these pioneering studies, and more focus is now placed on the role of stakeholders; there has also been a move away from top-down models of implementation towards bottom-up and hybrid models, which has been supplemented in recent years by complex network and systems thinking. Today the factors that shape and influence implementation are considered "complex, multifaceted and multileveled" (Hudson et al. 2019).

Another important discovery that has emerged from more recent research is the importance of adapting the implementation model to the local context (Hill and Hupe 2015).

The first mechanism to consider in the implementation process concerns the understanding of political decisions. Actors participating in the implementation process of a decision - authorities, organizations, and officials - must understand what the decision means in political terms, what the decision-makers want, and what is expected of them (Lewis and Seibold 1998). If the message is unclear, uncertainty and misunderstanding when implementing decisions in practice can result (Allen et al. 2007). The second mechanism concerns the number of actors involved in vertical chains of the implementation. The involvement of too many actors often culminates in no action at all, because actors are unable to reach consensus about how to interpret the political decision (Matland 1995). The third mechanism addresses the horizontal network of the implementation. The presence of too many stakeholders results in vast amounts of negotiation and information exchange. While being necessary and important, large horizontal networks can constitute obstacles (Goggin et al. 1990). The fourth mechanism involves street-level grassroots bureaucrats. It is these officials, who have direct contact with the citizens and are the last step in the implementation process, who in practice decide how political decisions are implemented. They need both freedom of action and capacity for action, including adequate resources (Lipsky 1980; Sevä 2013; see also Brodkin 2011 regarding the specific accountability of street-level bureaucrats). The final mechanism concerns the recipient of the implementation process, i.e. the citizens' opportunity to co-create the implementation (Nemoto and Biazoti 2017; van der Jagt 2017).

Rabe (2017) has discussed the role of citizen participation dialogues in Sweden. She has described the traditional consensus approach - the importance of reaching agreement on the best solution for the commons in society. The consensus approach has resulted in a rooted understanding that compromises are inevitable for societal development, and has been particularly established in Sweden due to a history of strong labour rights.

Consequently, according to Rabe (2017), obtaining acceptance, or consensual agreement among parties affected by a decision, is an essential part of the dialogue between citizens and officials in Sweden. This, in turn, implies that practical processes for exchanging stakeholders' consent are well developed. However, one of the challenges with the consensus approach is that it is usually the governing bodies that frame the problems and solutions and in practice are in the position of power. On the surface, the governing bodies' decisionmaking processes allow for citizen engagement and influence but exploring the actual unfolding of official decision-making suggests that citizen influence sometimes results in very few changes, which in turn paradoxically may lead to lesser citizen engagement (Rabe 2017). 


\section{Method}

\section{Neighbourhood Areas}

The city of Stockholm has 14 district areas, all of which were approached for participation in the study. Nine of the districts agreed to participate. This study thus investigates community gardening in nine districts: Bromma district; Enskede, Årsta Vantör district; Farsta district; Kungsholmen district; Skarpnäck district; Skärholmen district; Södermalm district; Älvsjö district; and Östermalm district (Figure 1). These areas are geographically dispersed and so they represent different parts of Stockholm. There is no comprehensive list of how many urban gardens there are on municipal land today, but in 2018 there were approximately 43 (Figure 1); the number varies every year, with new gardens being set up and others closing. Most current community gardens were started in the last 7 years (Bonow and Normark 2018); the majority are rather small (10-80 square metres), and between three and 20 people are usually actively involved in tending each garden. Most of the crops are grown in raised beds in pallet collars, i.e. wooden boxes, but crops are also planted directly in the ground in some of the newest ones.

Figure 1: Districts of Stockholm and the approximate number of urban gardens on municipal land. The figure is presented to provide an overview, the size and exact positions of the gardens are not completely geographically accurate

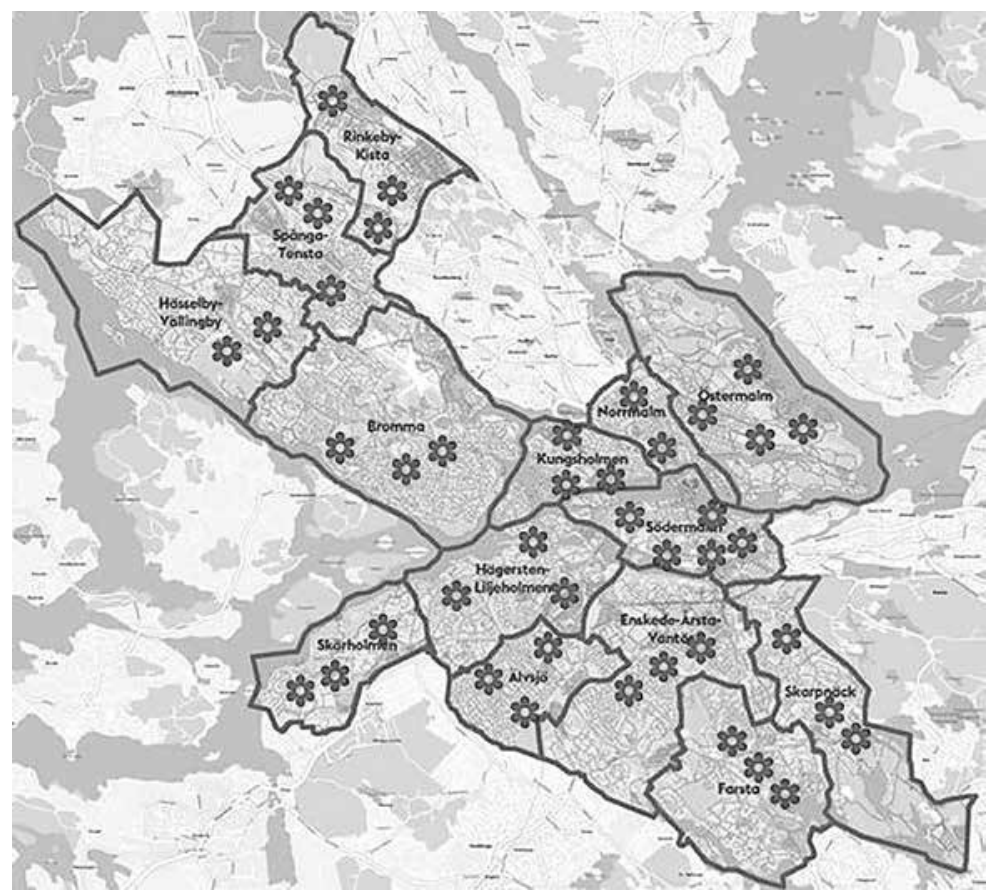

Source: Authors 


\section{Overview of Procedure}

In our study, the implementation process is examined from the perspective of the street-level bureaucrat, because according to implementation theory street-level bureaucrats are the most important link in the chain of governance and implementation (Lipsky 1969, 1980; Hupe and Hill 2007). In this case, park engineers are responsible for the operation and maintenance of planned parkland in each district area. They are in a position to assess how clear the guidelines are, what resources are available, and what obstacles arise. In addition, they have contact with many of the city's actors, such as individual citizens, groups, and other administrative bodies, and thus have knowledge of the various players' involvement in community gardening. All of these factors are crucial for the successful implementation and survival of community gardening.

Park engineers from the aforementioned nine district administrations were interviewed using the semi-structured interviewing method. The questions in the interview form were prepared according to the mechanisms of the implementation process presented in the theory section of this paper, in other words: political decisions; the vertical chains of implementation; the horizontal networks of implementation; individual street-level grassroots bureaucrats; and the recipients of the implementation process.

Three of the semi-structured interviews were carried out by telephone and the others by e-mail, due to the wishes of the informants. While e-mail interviews indeed have some limitations, lacking the potential for immediate follow-up clarifications and discussions, this was the best opportunity to collect data from as many informants as possible. Since the interviews were semi-structured, they were phrased in the same way to all informants. The telephone interviews were recorded with the respondents' approval and transcribed. We used a thematic analysis (Braun and Clarke 2006), identifying patterns or themes within our qualitative data. We then compared the patterns that were found with previous research in the field and with the theoretical perspectives, using a three-step process: (1) reduction of data (coding); (2) presentation of data (thematization); (3) conclusions and verification (summation).

The analysis of the material was done in several rounds, where coding, thematization, and summation were done alternately and in parallel, until no new observations were made. The coding resulted in a so-called thematic framework which was then used for the rest of the analysis (Clarke and Braun 2013).

Since all officials did not agree to have their names published in the study, the decision has been made that all participants will remain anonymous. From here on, the interviewees will be called "park engineer(s)", and to increase the level of anonymity none of the statements will be linked to individual respondents' names or district areas; they are, however, numbered as park engineer 1-9 (PE1-9) so that it will be possible to follow the line of argument from the respondents, especially in the quotes. All quotes have been translated by the authors from Swedish to English.

\section{Analysis of Governing Documents}

As a first step in analyzing how community gardening has unfolded locally, we carefully studied a number of governing documents. The most comprehensive document for the city and its 
green structure is the Stockholm comprehensive plan, the Promenadstaden (Stockholms Stad originally 2010, revised 2018). This document builds on Stockholm's vision for the future, Vision 2040. In addition to the Promenadstaden, there is also the steering document Stockholms miljöprogram 2016-2019. The Promenadstaden was also supplemented by Den gröna promenadstaden, which was intended to serve as a steering document with specific goals, strategies, and guidance for how the city's green areas should be developed and managed (Stockholms Stad 2013).

All these plans have been incorporated in a newer document, Grönare Stockholm basically, guidelines for planning, implementation, and management of the city's parks and nature areas. This also serves as a strategic guide for Stockholm's politicians and officials in their work on the city's parks and green areas (Stockholms Stad 2017b).

Each district administration also has its own local park plan (Parkplanen) for the management and development of green areas (Stockholms Stad 2018b), in which Grönare Stockholm's guidelines should be clarified. Grönare Stockholm's guidelines are also found in thematic knowledge bases and planning tools. The park plans, the knowledge base, and the planning tools should, in theory, all function to guide the work of the officials who oversee parks and green areas (Stockholms Stad 2017b).

\section{Empirical Findings}

Based on our implementation theory analysis, we now present some results regarding the challenges and obstacles described by the park engineers (labelled PE1-PE9 below).

\section{Understanding Political Decisions}

All of the park engineers expressed a desire and a need for common guidelines for the city regarding community gardening, as the current documents are unclear. The Stockholm City Council has decided to work towards sustainable urban development, a decision that includes community gardening (PE5). Most park engineers have requested more explicit guidelines in light of this decision, but have not received any kind of hearing:

We should not sit here each one and find our own truth. It should come from above. End of discussion. (PE5)

Despite statements like this, a minority believe that it is clear what is expected of them regarding community gardening (PE2, 3), although the rest consider community gardening to be a challenging issue. Some also experience a problem with the concept of community gardening and how this should be handled since no clear definition is found in the available documents (PE4, 5, 6, 7).

PE5 expressed it thus:

It is confusing with the various documents that exist within the city when they are not communicated clearly and directly, and they keep on changing. Those on the administration sit with so much else on their plate and then there is no way to keep track of when different documents are removed. (PE5) 
This is a recurring theme from the park engineers, who express dismay that it is difficult to keep track of the city's documents since there are too many of them and they are not properly communicated (PE1, 3, 4, 5, 6, 7, 8, 9). There is also uncertainty about how the various documents are linked to each other.

Regarding political decisions, we conclude that neither the goals of community gardening nor the sources of funds with which the goals are to be achieved seem sufficiently clear. Although most park engineers have requested clearer guidelines, they have not been developed. The current imprecise guidelines may of course - just as implementation theory suggests - be a conscious strategy on the decision-makers' part, deliberately intended to create the space in which the concept of community gardening can be interpreted in various ways by individual civil servants (who may already know that it is difficult to treat community gardening in the same way in all district areas). But it could also be that this ambiguity is deliberate since the politicians are themselves unsure about how community gardening initiatives should be implemented (Bonow and Normark 2018).

\section{Communication in Vertical Chains of Implementation}

The current incarnation of implementation theory states that the presence of too many actors makes implementation and decision-making difficult. However, in this case our analysis shows the opposite; the involved actors, especially the voice of the centralized decisionmakers, are actually absent from the implementation processes.

Some of the district councils' interest in community gardening has increased (PE1, 3,6 ), while in others it has decreased (PE4, 8, 9): but none of the respondents had contact with the politicians above their district council, and thus communication was limited to the politicians on a local level. Because of this, most of the park engineers had no knowledge of how interest in community gardening is perceived on a higher governing level. However, some park engineers mentioned that politicians (above the committee level) have stated in official documents that they wanted the officials to support and encourage community gardening in new places $(\mathrm{PE} 1,2)$. One park engineer said that community gardening is not a priority among local politicians (PE4), while others believe that some have a genuine interest in community gardening:

There is definitely an interest from the politicians ... The chairman of our board is from the Green

Party, so she is particularly interested. And in our neighbouring district the chairman of the board is a member of a small garden association and has his own raised bed [where he gardens] so he thinks it is fun. (PE2)

But overall, the district councils' goals for community gardening and what was required by the officials are considered to be unclear, even in the district administrations where the politicians were involved.

Some park engineers commented on the lack of clarity from actors higher up in the vertical chains, which they suggested hampers development. They also experienced a lack of basic organization and structural linkage between the actors (and within their district administration) (PE1, 5, 8). On some occasions, information had not been passed down to the officials 
and therefore various misunderstandings have occurred. The experience of other park engineers was that communication and collaboration with local politicians worked sufficiently well, but that their local politicians simply had unclear goals for community gardening (PE1, $2,3,4,5,8)$.

Regarding communication on a vertical level in the governing organizations, our data thus shows two limitations to the implementation of community gardening: either the decision-makers lack an actual purpose with community gardening, or they fail to communicate the purpose to those at a level where the decisions are implemented.

\section{Communication in Horizontal Networks}

Communication and cooperation are generally said to work well between the actors in horizontal networks (PE1, 2, 3). However, there are still, to some extent, shortcomings in horizontal communication, mainly due to the distribution of responsibilities between many actors. While in vertical networks, we learned that deciding actors are absent from the process, responsibilities are diffused in the horizontal networks among many local actors with the inevitable consequences of confusion and uncertainty.

Two park engineers stated that their district administrations have sought to engender cooperation between all of the district administrations in the city in a bid to develop common guidelines (PE1, 7). However, that did not happen, as some districts felt that their administrations need to work in specific ways because of different conditions for community gardening in each district $(\mathrm{PE} 4,5)$. One such reason concerned the significant differences in demographics between districts:

The interest in community gardening [among the citizens] is relatively low compared to other districts. Why that is, is beyond my area of expertise. In part, I think it has to do with demographics and income levels. (P8)

Another respondent (P9) mentioned "the [district's] lack of land available and suitable for community gardening". Because of these differences, some district administrations have developed common guidelines together while others have produced their own independently (PE1, 2, 3).

While local adaptations are important to fit the needs of the districts and their citizens, this results in two things: firstly, work with processes and guidelines is duplicated rather than coordinated among various districts; secondly, the work that is supposed to be coordinated between districts is delayed due to the excessive number of district actors. This coordination problem could to some extent be explained by the lack of guidelines from central decisionmakers in the city and arguably be solved by better communication in the vertical chain. But even though an excess of players can cause problems, implementation theory suggests that the actors would be more effective if they were working together to solve problems. In other words, the horizontal networks are crucial in the implementation of a decision and it is therefore of great importance that cooperation and communication are as effective as possible. 


\section{Street-level Grass-roots Bureaucrats}

This part of the implementation theory analysis focuses on the everyday implementation and practices of the administrators that meet with citizens. As described above, each district administration has rules that frame and define how and where community gardening may be allowed. The local rules differ, for example, regarding whether the permit for the cultivation requires an association or an individual person, and what, if any, resources the district administration provides. Our data indicate three kinds of interactions that we describe below.

\section{Providing Resources (Land and Equipment)}

District administrations support their citizens to varying degrees, but they all offer pallet collars to use as raised beds as well as topsoil. The biggest difference concerns the water supply; some offer their urban gardeners water and others do not. Differences are also seen in how encouraging the different district administrators are towards their citizens who are seeking to initiate community gardening projects.

Most of the respondents felt that the availability of land poses a problem, and that community gardening collides with other green area interests. Some cultivation sites that currently exist may be moved in the future to make room for other things, and indeed one of the largest and earliest community gardens has just recently moved to a new location. The moves of community gardens that we have a record of (there are no official statistics available) have exclusively been the result of changes in city planning and development; the municipality wants to use the land for other purposes.

Some park engineers, especially from the central districts, expressed the view that community gardening is not prioritized by the politicians because it is just one of many competing interests in the district. In contrast, in a few of the more suburban districts the politicians do prioritize community gardening over other interests.

\section{Active Encouragement of Citizens}

Examples of active encouragement are advertising in the local press about cultivation opportunities and the spontaneous provision of cultivation boxes (PE1, 3, 6), tactics that have also been reported in areas where community gardening is less developed. This sort of thing has occurred even though some of the respondents said that they have a passive role in encouragement. Some of the district administrations also discussed setting up signs in places that they consider appropriate for cultivation to try to encourage citizens (PE3, 6). One district is taking it even further: in some major park investment projects they are collaborating with the Traffic Office or the Development Office to try and ensure that special areas for community gardening are built from the start when new areas are constructed (PE5). Citizens can then register interest and do not need to find a suitable place for gardening by themselves, which is in itself a development of community gardening which in turn is described as generating elevated levels of ambition and interest.

Seven of the respondents believed that resources are not, and will not be, a big issue provided that community gardening stays at the current level with the same goals as of today. In essence, they believe that community gardening is not a particularly complicated or resource-intensive activity to organize. However, one of them stated that the resources 
available are not enough for everything they would like to develop; another said that it would still be good to have more time because they would then have the opportunity to engage more citizens. Some of the park engineers claimed that a lack of resources may become a (major) problem in the future if the interest in community gardening continues to grow.

\section{Organizational Resources (Time and Funds)}

The politicians in some districts have not given priority to community gardening because of a lack of resources and interest. This is reflected in the fact that most of the park engineers said that they have limited staff, time, and financial capacity available to utilize. According to the park engineers, district administrations simply cannot spare staff time to help their community gardens as much as they would like, and due to lack of financial resources some cannot even afford to supply water - an obvious and serious handicap to any gardening project.

\section{Citizens: The Ultimate Recipients of the Implementation}

This final part of our analysis focuses on the experiences of citizens. In the study so far, we have focused on the role of the governing administration, a decision based on our assumption that the development of grass-roots projects such as community gardening on public land is largely dependent on the benevolence of the authorities. But our data suggest that there is an important interplay between the level of interest from the citizens and the politicians. In the following section we will present the reasons how the park engineers experience the particular level of citizen engagement in their districts.

Four of the park engineers mentioned that the demand for community gardening was low in their district areas (PE2, 4, 7, 8). The park engineer in one inner city area said:

On the part of the citizens it [the demand] is not huge. It is not the case that every person wants to grow. (PE2)

According to PE4, this lack of interest may be due to other green interests being more important to the district citizens. PE4 also had the impression that people's need for cultivation and nature can be met in other ways. In one of the other districts, the park engineer's experience was that there is "absolutely an interest in community gardening but it is not huge, and it is common for people to lose interest after they have grown for a while" (PE1). But a contrasting experience was also registered: "the citizens' interest in cultivation is great and the citizens are very involved in their living environment" (PE3). One park engineer expressed the view that urban cultivation is ““...of its time'. It is popular and trendy to 'do things yourself': grow, work in the garden, brew one's own beer and so on" (PE1). The patterns we notice show that interest is lower in the suburban areas than in the inner city, although it differs between the southern part of the inner city where the interest seemed greater than in the northern part.

These varying levels of engagement are interesting and should be considered alongside the perspectives of the gardeners themselves that were developed in our earlier work (Bonow and Normark 2018). In order to maintain focus on the administration, we may note that the relationship between demographics and class influences interest in community gardening. 
But we also notice that some of the park engineers (PE2, 4, 7, 8) who described low levels of interest from the citizens work in those districts that, according to the data, do not actively encourage citizens to take up community gardening in comparison to the districts that actively encourage it (PE1, 3, 5, 6).

\section{Discussion}

\section{Opportunities for Initiatives}

Although it varies between the district administrations, public interest in community gardening generally seems to exist throughout Stockholm; this increases the chances of successful implementation and long-term survival since citizens' involvement is so crucial (Nemoto and Biazoti 2017; van der Jagt 2017; Prové et al. 2016: 17, 23). Previous studies have shown that it is of great importance that citizens can influence the decisions which are made about their surroundings (Nemoto and Biazoti 2017; van der Jagt 2017). The citizens in all nine district administrations in the study seem to have the opportunity to influence the occurrence and development of community gardening, although their desire cannot always be satisfied for various reasons. Some park engineers seem to be more involved in communicating with the citizens and their ability to influence is greater than others, which suggests that community gardening has a greater chance of being implemented, developed, and surviving/thriving more in some of the neighbourhood areas than in others.

Previous research shows that the support and initiatives of different actors play crucial roles in the survival of community gardening (Prové et al. 2016; van der Jagt et al. 2017), a finding which is confirmed in this study. For example, the degree of involvement of local politicians has a direct impact on how the officials prioritize community gardening in their work: the areas where the district councils are not interested have less community gardening.

The politicians' framing of community gardening in the district councils is generally unclear, even in the district councils that are positively disposed towards the issue. Since it is important to have clear instructions according to the theoretical framework (Hupe 2011; Saldivar-Tanaka and Krasny 2004; van der Jagt et al. 2017), ambiguity flowing from the committees can be assumed to affect the work of the park engineers with community gardening and thus the occurrence of the phenomenon. Some of the park engineers confirm that they find it difficult to make progress with community gardening because of the lack of clarity from politicians both in and above the district councils. This indicates that local politicians do not prioritize community gardening, and that makes it difficult for the survival and resilience of garden projects.

Imprecision in framing can, however, result in effectiveness of implementation, and legitimacy can also increase as ambiguity can create freedom of action (Lipsky 1980). But in the case of Stockholm it seems to work the opposite way. Even if the unclear guidelines are a conscious strategy of the decision-makers, some of the park engineers find them difficult to cope with, which in turn results in a negative impact on the development of community gardening. The same thing has been discussed in relation to the implementation of ecosystem services in Stockholm (Kaczorowska et al. 2015). 
The nature of the task that the district administrations have in encouraging and supporting citizens who wish to garden differs between the districts. All offer pallet collars and topsoil, which is certainly a positive thing, but this does not seem to be enough. The fact that the level of support differs is not surprising, as municipal commitment to gardening and access to resources varies. The district administrations that support their growers are those which seem to have a serious commitment to cultivation: they have prioritized it and also have enough resources to support it. Higher support is also observed in the districts where there is the largest public interest (greater citizen interest can certainly also lead to an increased interest on the part of the district administration).

Since the municipality's support is so crucial for the survival of the cultivation, the low level of support - or its complete absence - from some district administrations is a negative factor (Redwood 2009; van der Jagt et al. 2017).

\section{Sharing Resources}

The fact that some of the district administrations can - and do - cooperate with each other over this issue is undoubtedly a positive thing. Overall, it is those bodies which work closely with other district administrations that have a more positive view of communication and cooperation. In general, interest in gardening among other actors in the horizontal networks seems to exist but differs between the district administrations. Involvement is crucial for success (Prové et al. 2016; van der Jagt et al. 2017), and it undermines thriving and resilient community gardening in Stockholm if general interest is lacking.

Due to a lack of resources, it is challenging for some of the district administrations to work with community gardening, partly because they cannot provide the citizens with the necessary support. The resource shortage is mainly about a shortage of suitable land, something which has been seen in other studies as well (Nemoto and Biazoti 2017; Prové et al. 2016; Cohen and Reynolds 2014); time, financial capacity, and staff are also lacking in some cases. Some park engineers argue that there are enough resources now, but that there may be a problem if interest in community gardening goes on increasing. Too few resources are negative for the implementation and development of community gardening as these are of crucial importance (Saldivar-Tanaka and Krasny 2004; van der Jagt et al. 2017). However, sometimes community gardening has been given priority over other interests, and where this is so private cultivation of public spaces thrives.

All of the interviewees argued without exception that because of the different conditions in each district, the lack of central guidelines, divided responsibilities, and how community gardening is viewed, each of the district administrations works differently. All of the park engineers were aware of each other's different conditions, and everyone agreed that it is important that there is some form of equality and cooperation. They claimed that there should be no difference in the possibility of gardening regardless of where in the city someone lives. 


\section{Conclusions}

The analysis shows that different local conditions and actions in the districts of Stockholm significantly affect the initiative of the park engineers, which in turn, indirectly, affects citizens' initiatives. As earlier reported by Prové et al. (2016) and Redwood (2009), we have found that the reason for the difference in the presence of community gardening within the City of Stockholm is that there is a lack of proper support from certain district councils and district administrations to the citizens who want to set up gardens. The municipalities whose district council and district administration are less interested in the issue have fewer community gardens than the others. The analysis suggests that the lack of bottom-up initiatives from citizens may stem from the lack of outreach initiatives by the officials in some districts. This can be explained by the effects of the consensus approach in Sweden (see e.g. Rabe 2017).

Furthermore, as discussed by van der Jagt et al. (2017), we can also see that one of the reasons that community gardening is not expanding in Stockholm seems to be the lack of clear guidelines for street-level bureaucrats. It is difficult for officials to work in a uniform manner and to provide opportunities for community gardening if no specific requirements are set on how it is supposed to be integrated in the sustainable development of the green areas in the city (see also van der Jagt et al., 2017). Finally, the local access to, and sharing of, resources and expertise also varied between the district administrations, and where these assets were lacking or inadequate it resulted in some district administrations having fewer community gardens than others. Some of the variations in resource levels can be explained by local decisions regarding funding priorities and by the effects of centrally determined policies (Cockrall-King 2012).

While the earlier studies have pointed out the need for political engagement and support, this study gives a concrete example of how the dependencies among the governing official organizations play out in practical experience. It leads us to the conclusion that community gardening in Stockholm in general depends too heavily on the organizational conditions and cultivation knowledge of park engineers in the local implementation structure, instead of on a thoroughly thought-out and vertically coordinated general implementation plan.

\section{References}

Åberg, Ida. 2019. Imagining Urban Gardening Space an Ethnographic Study of Urban Gardening in Sweden. FiF-avhandling (Doctoral Dissertations) No. 125, Linköping University.

Allen, James, Nerina L. Jimmieson, Prashant Bordia, and Bernd E. Irmer. 2007. "Uncertainty during Organizational Change: Managing Perceptions through Communication." Journal of Change Management 7(2): 187-210.

Bonow, Madeleine and Maria Normark. 2018. "Community Gardening in Stockholm: Participation, Driving Forces and the Role of the Municipality." Renewable Agriculture and Food Systems 33(6): 503-517.

Braun, Virginia and Victoria Clarke. 2006. "Using Thematic Analysis in Psychology." Qualitative Research in Psychology 3: 77-101. 
Brodkin, Evelyn Z. 2011. "Policy Work: Street-Level Organizations under New Managerialism.” Journal of Public Administration Research and Theory 21: 253-277.

Certomá, Chiara and Bruno Notteboom. 2017. "Informal Planning in a Transactive Governmentality. ReReading Planning Practices through Ghent's Community Gardens.” Planning Theory 16(1): 51-73.

Clarke, Victoria and Virginia Braun. 2013. "Teaching Thematic Analysis: Overcoming Challenges and Developing Strategies for Effective Learning." The Psychologist 26(2): 120-123.

Cockrall-King, Jennifer. 2012. Food and the City: Urban Agriculture and the New Food Revolution. New York: Prometheus Books.

Cohen, Navin and Kristin Reynolds. 2014. "Urban Agriculture Policy Making in New York's 'New Political Spaces': Strategizing for a Participatory and Representative System.” Journal of Planning Education and Research 34(2): 221-234.

Goggin, Malcolm L., Ann O. Bowman, James P. Lester, and Laurence J. O’Toole Jr. 1990. Implementation Theory and Practice: Toward a Third Generation. Harper Collins Publishers.

Göteborgs stad. 2019. Retrieved September 27, 2019 (https://stadsnaraodling.goteborg.se/om-oss/).

Hill, Michael and Peter Hupe. 2015. Implementing Public Policy: Governance in Theory and Practice. 3rd ed. London: Sage Publications.

Hupe, Peter and Michael Hill. 2007. "Street-Level Bureaucracy and Public Accountability." Public Administration 85(2): 279-299.

Hupe, Peter L. 2011. "The Thesis of Incongruent Implementation: Revisiting Pressman and Wildavsky." Public Policy and Administration 26(1): 63-80.

Kaczorowska, Anna, Jaan-Henrik Kain, Jakub Kronenberg, and Dagmar Haase. 2015. "Ecosystem Services in Urban Land Use Planning: Integration Challenges in Complex Urban Settings - Case of Stockholm." Ecosystem Services 22: 204-212.

Lewis, Laurie K. and David R. Seibold. 1998. "Reconceptualizing Organizational Change Implementation as a Communication Problem: A Review of Literature and Research Agenda." Annals of the International Communication Association 21(1): 93-152.

Lipsky, Michael. 1969. Toward a Theory of Street-Level Bureaucracy. University of Wisconsin.

Lipsky, Michael. 1980 [2010]. Streel-Level Bureaucracy: Dilemmas of the Individual in Public Services. Russell Sage Foundation.

Matland, Richard E. 1995. "Synthesizing the Implementation Literature: The Ambiguity-Conflict Model of Policy." Journal of Public Administration Research and Theory 5(2): 145-174.

McClintock, Nathan. 2014. "Radical, Reformist, and Garden-Variety Neoliberal: Coming to Terms with Urban Agriculture's Contradictions.” Local Environment 19(2): 147-171.

Nemoto, Eliane Horschutz and André Ruoppolo Biazoti. 2017. "Urban Agriculture: How Bottom-Up Initiatives are Impacting Space and Policies in São Paulo. Future of Food." Journal on Food, Agriculture and Society 5(3): 21-32.

Pölling, Bernd. 2016. “Comparison of Farm Structures, Success Factors, Obstacles, Clients' Expectations and Policy Wishes of Urban Farming's Main Business Models in North Rhine-Westphalia, Germany." Sustainability 8(5): 446.

Pressman, Jeffery L. and Aaron Wildavsky. 1973. Implementation: How Great Expectations in Washington are Dashed in Oakland. Los Angeles: University of California Press.

Prové, Charlotte, Joost Dessein, and Michiel de Krom. 2016. "Taking Context into Account in Urban Agriculture Governance: Case Studies of Warsaw (Poland) and Ghent (Belgium)." Land Use Policy 56: 16-26.

Rabe, Linn. 2017 Participation and Legitimacy Actor Involvement for Nature Conservation. Södertörn Doctoral Dissertations 128 Stockholm.

Redwood, Mark, ed. 2009. Agriculture in Urban Planning - Generating Livelihoods and Food Security. London: Earthscan. 
Sabatier, Paul A. and Daniel A. Mazmanian. 1983. Can Regulation Work? The Implementation of the 1972 California Coastal Initiative. New York: Plenum Press.

Saldivar-Tanaka, Laura and Marianne E. Krasny. 2004. "Culturing Community Development Neighbourhood Open Space, and Civic Agriculture: The Case of Latino Community Gardens in New York City." Agriculture and Human Values 21(4): 399-412.

Sevä, Mikael and Sverker Jagers. 2013. "Inspecting Environmental Management from within: The Role of Street-Level Bureaucrats in Environmental Policy Implementation.” Journal of Environmental Management 128: 1060-1070.

Stadsodling Malmö 2019. Retrieved September 30, 2019 (https://stadsodlingmalmo.se/).

Stockholms Stad. 2013. "Den gröna promenadstaden [The Green Promenade].” Retrieved November 13, 2017 (https://vaxer.stockholm.se/globalassets/tema/oversiktsplanen/den-grona-promenadstaden. pdf).

Stockholms Stad. 2017b. “Grönare Stockholm [Greener Stockholm].” Retrieved November 14, 2017 (https:/vaxer.stockholm.se/globalassets/tema/utemiljo/trk277-gronare-stockholm-a4.pdf).

Stockholms Stad. 2018a. "Översiktsplan för Stockholm [Stockholm Overview Plan].” Retrieved Mars 10, 2018 (http://vaxer.stockholm.se/tema/oversiktsplan-for-stockholm/).

Stockholms Stad. 2018b. "Parkplaner [Park Plans].” Retrieved March 15, 2018 (http://www.stockholm. se/KulturFritid/Park-och-natur/Parker/Parkplaner/).

Tornaghi, Ciara. 2014. "Critical Geography of Urban Agriculture.” Progress in Human Geography 38(4): 551-567.

van der Jagt, Alexander P. N., Luca R. Szaraz, Tim Delshammar, Rozalija Cvejić, Artur Santos, Julie Goodness, and Arjen Buijs. 2017. "Cultivating Nature-Based Solutions: The Governance of Communal Urban Gardens in the European Union.” Environmental Research 159: 264-275.

\section{Authors}

Madeleine Bonow is Associate Professor in Geography at the School of Natural Sciences, Technology and Environmental Studies, Södertörn University in Stockholm, Sweden. Bonow's research areas concern landscape changes both within the city where urban cultivation has been the focus and the peri-urban landscape's structural transformation from agricultural landscape to a recreational landscape inhabited by horses. Another area of interest is how to promote regional development through small-scale food production.

Contact: madeleine.bonow@sh.se

Maria Normark is Associate Professor in Media Technology at the School of Natural Sciences, Technology and Environmental Studies, Södertörn University in Stockholm, Sweden. Normark's research concerns the development of grassroots movements in relation to digital design. More specifically, she focuses on situated practice and social exchange in entanglement with (digital) materials and material qualities.

Contact: maria.normark@sh.se

Sabine Lossien is graduate from the BA programme in environmental science at the School of Natural Sciences, Technology and Environmental Studies at Södertörn University. Contact: sabinelossien@hotmail.com 